\title{
Long Walks in Hierarchical Porous Materials due to Combined Surface and Configurational Diffusion
}

\author{
Vivek Vattipalli ${ }^{1}$, Xiaoduo $\mathrm{Qi}^{1}$, Paul Dauenhauer ${ }^{2}$, and Wei Fan ${ }^{1 *}$
}

1. Department of Chemical Engineering, University of Massachusetts Amherst, 686 North Pleasant Street, Amherst, Massachusetts 01003 United States

2. Department of Chemical Engineering and Materials Science, University of Minnesota, 421 Washington Ave. SE, Minneapolis, MN, 55455 United States of America

E-mail: wfan@engin.umass.edu 


\section{ZLC experiments:}

The design of the experimental setup used has been described in our previous work. ${ }^{1}$ The ZLC experiment involves allowing a small quantity of adsorbent to equilibrate with a gas stream consisting of probe molecule and inert gas. In our experiments, the probe molecule used was either cyclohexane or 1methylnaphthalene, while the inert gas used was nitrogen. For each of the probe molecules, the exact same conditions were used to measure diffusivities in all the adsorbent samples. The experiments were done within the Henry's law region, so that the diffusivities could be obtained by using the short-term and long-term analysis methods. ${ }^{2}$ The diffusivities obtained using the ZLC method are transport diffusivities, but since these measurements are run at very low concentrations, these values are not very different from the self-diffusivities. Further details have been provided in the data analysis section of this supporting information. A number of different tests were done to validate the setup as well as the results, which have been described later.

\section{ZLC data analysis:}

The main assumptions of the ZLC models developed by Ruthven et al. are perfect mixing in the cell, equilibrium at gas-solid interface and that the holdup in gas phase is not significant. ${ }^{3-4}$ Considering the particles to be spherical and three-dimensional diffusion, there is an infinite-series solution for normalized concentration in the gas desorption stream:

$$
\frac{c}{c_{0}}=2 L \sum_{n=1}^{\infty} \frac{\exp \left(-\frac{\beta_{n}^{2} D_{e f f}}{R^{2}} t\right)}{\left[\beta_{n}^{2}+L(L-1)\right]}
$$

where $c$ is the gas phase adsorbate concentration, $c_{0}$ is the initial gas phase adsorption concentration, $R$ is the radius of the particle, $D_{e f f}$ is the effective diffusivity and $t$ is the time. $L$ is defined as:

$$
L=\frac{1}{3} \frac{F R^{2}}{K V_{s} D_{e f f}}
$$

where $F$ is the purge gas flow rate, $K$ is the Henry's law constant and $V_{s}$ is the volume of adsorbent. $\beta_{n}$ satisfies the following condition:

$$
\beta_{n} \cot \beta_{n}+L-1=0
$$


The FID response from the ZLC experiment is converted to the dimensionless concentration according to the following relationship:

$$
\frac{c}{c_{0}}=\frac{I(t)-I_{\infty}}{I_{0}-I_{\infty}}
$$

where $I(t)$ is the FID signal at any time $t, I_{\infty}$ is the background FID signal (seen at long time) and $I_{0}$ is the initial FID signal.

In the long-time region, the solution of equation 1 can be reduced to:

$$
\frac{c}{c_{0}}=2 L \frac{\exp \left(-\frac{\beta_{1}^{2} D_{\text {eff }}}{R^{2}} t\right)}{\left[\beta_{1}^{2}+L(L-1)\right]}
$$

In order to use this method, a plot of $\ln \left(c / c_{0}\right)$ is made against time and the slope of the plot at long time was fed to the above equation to extract the value of $D_{e f f} / R^{2}$.

For cyclohexane measurements, nitrogen was bubbled through a liquid cyclohexane column whose temperature was maintained using a water bath and subsequently diluted with another nitrogen stream. When the gas stream at the outlet of the bubbler is completely saturated, the partial pressure of cyclohexane is $5.6 \times 10^{-6}$ bar, which would correspond to the Henry's law region in the published isotherms for the materials used. ${ }^{5-7}$ The data was analyzed using the long time analysis method.

For 1-methylnaphthalene measurements, when the gas stream at the outlet of the bubbler is completely saturated, the partial pressure of 1-methylnaphthalene is $8.9 \times 10^{-6}$ bar, which would correspond to the Henry's law region in a published isotherm for 1-methylnaphthalene adsorbed in a similar material (MCM-48). ${ }^{8}$ The data was analyzed using the short time analysis method which involves the use of the initial portion of the ZLC response curve to extract a value for diffusivity. ${ }^{5}$ Analyzing the data at short time has the added advantages of being less sensitive to errors from baseline drift and particle size distribution. In particular, due to the low vapor pressure used in the measurement for 1methylnaphthalene, long time analysis is significantly affected by the baseline drift. Therefore, short time analysis method was used. An approximate solution to the system for a step change in surface concentration is the following:

$$
\frac{c}{c_{0}} \approx \frac{1}{L}\left(\sqrt{\frac{R^{2}}{\pi D_{e f f} t}}-1\right)
$$


This equation is valid for $c / c_{0}<0.2$ and $L>10$.

A similar equation may be obtained as a solution for a one-dimensional diffusion path with $R$ replaced by $l$ as shown by Cavalcante et al. ${ }^{3}$ They also describe a method to help choose which of the two models should be used. They showed that if the $y$-intercept of a plot between $c / c_{0}$ and $1 / \sqrt{t}$ is negative, the three-dimensional model may be used. On the other hand, if the y-intercept of this plot is zero, the one-dimensional diffusion analysis method is used. As per this condition, the applicability of the three-dimensional model for these experiments was verified (Figure S1 shows the same in the case of cyclohexane and 1-methylnaphthalene diffusion in SBA-15 $6.2 \mathrm{~nm}$ ).

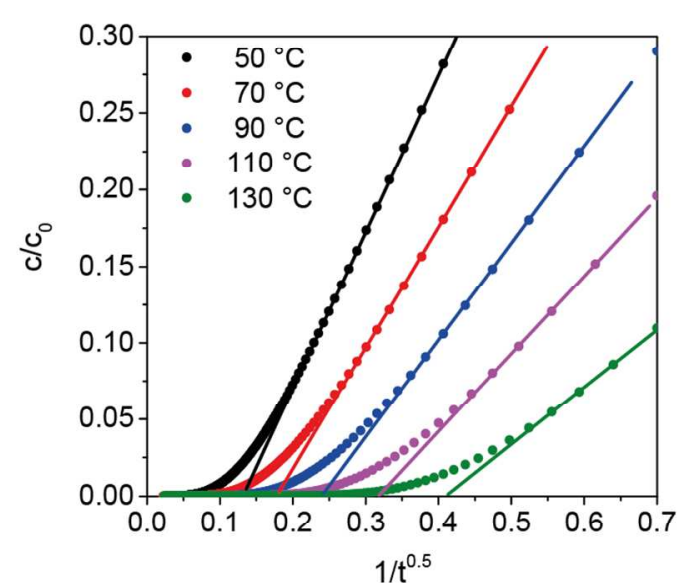

(a)

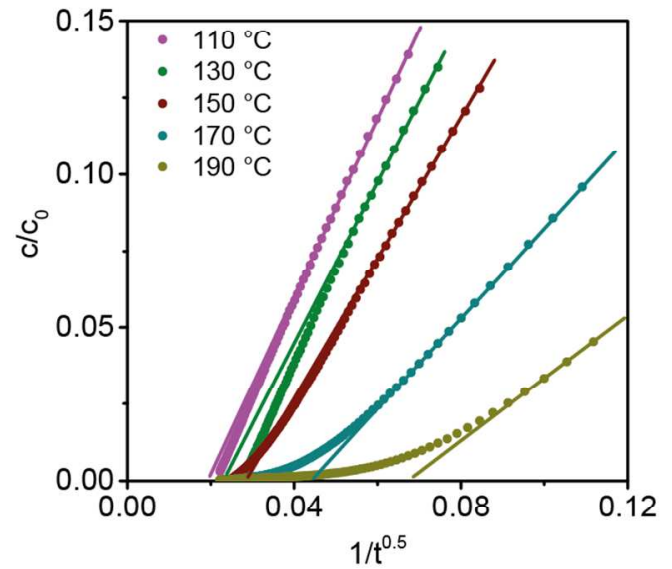

(b)

Figure S1. Plots of $\mathrm{c} / \mathrm{c}_{0}$ and $1 / \sqrt{ } \mathrm{t}$ for (a) cyclohexane and (b) 1-methylnaphthalene diffusion in SBA-15 $6.2 \mathrm{~nm}$. These show a negative y-intercept demonstrating the applicability of the three-dimensional model to these experiments.

\section{Validation of the ZLC setup}

1. Comparison with literature data

In order to benchmark our ZLC setup, the diffusivity of cyclohexane in $3 \mu \mathrm{m}$ silicalite-1 was measured (Figure S2) and compared with literature. The diffusivities obtained from these measurements match reasonably with other published studies for similar systems. ${ }^{5,9-11}$ 


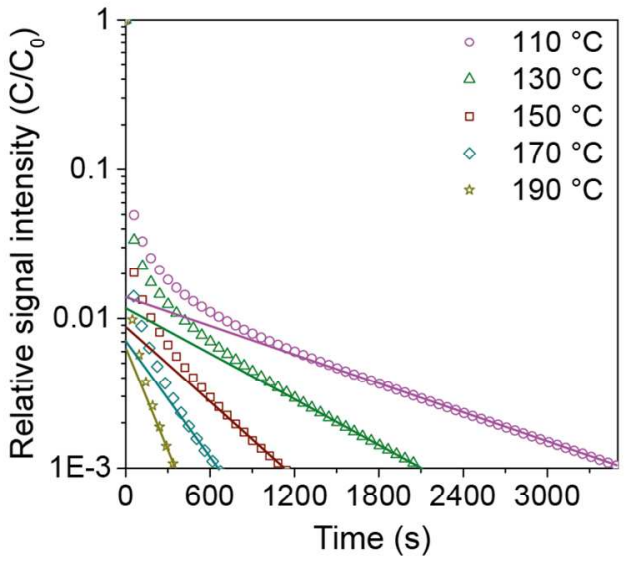

(a)

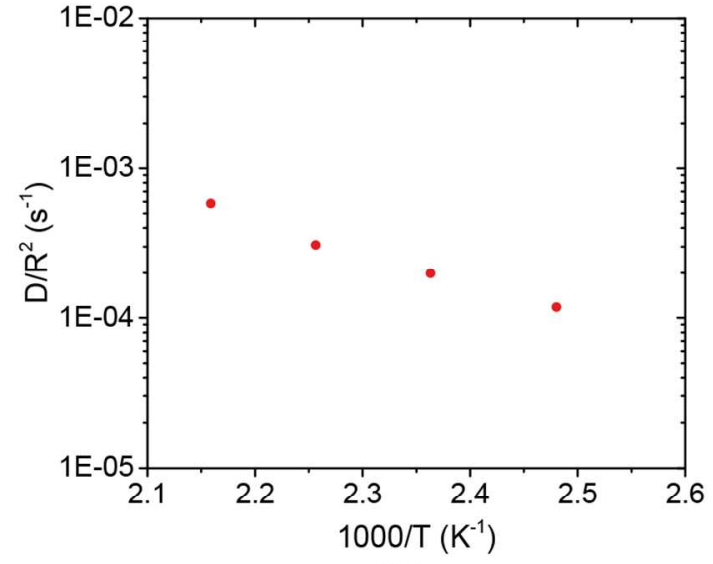

(b)

Figure S2. (a) ZLC curves and (b) Derived diffusivities of cyclohexane in $3 \mu \mathrm{m}$ silicalite-1 as measured using our ZLC setup. 
2. Equilibrium adsorption time

Brandani and Ruthven ${ }^{12}$ concluded that an adsorption time of at least $0.5 R^{2} / D$ is required when the value of $L$ is large. For our measurements with cyclohexane and 1-methylnaphthalene on the different porous materials, the adsorption time afforded ranged from $2 R^{2} / D$ to $5 R^{2} / D$ depending on the specific conditions such as value of $L$.

\section{Repeatability of the ZLC measurement}

ZLC measurements were repeated at least once to ensure repeatability of the data obtained. The repeated measurements for the case of cyclohexane diffusion in SBA-15 $5 \mathrm{~nm}$ are showing in Figure S3.

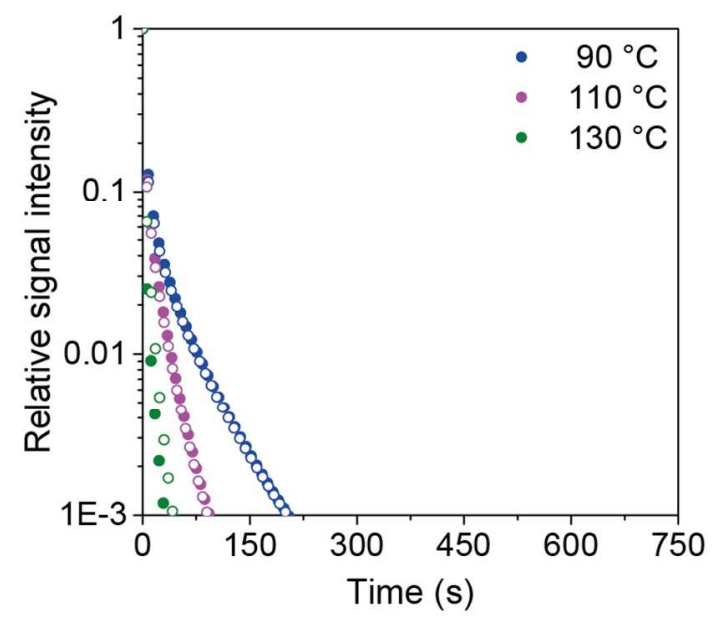

Figure S3. ZLC curves obtained from repeated measurements for cyclohexane diffusion in SBA-15 $5 \mathrm{~nm}$. The solid and empty dots represent two different sets of measurements.

4. Flow rate measurement

The existence of diffusion-controlled regime was also checked by running the ZLC measurements at different flow rates. Figures S4 and S5 show the ZLC curves and corresponding Arrhenius plots for the case of cyclohexane and 1-methylnaphthalene diffusion in SBA-15 $8.5 \mathrm{~nm}$. 


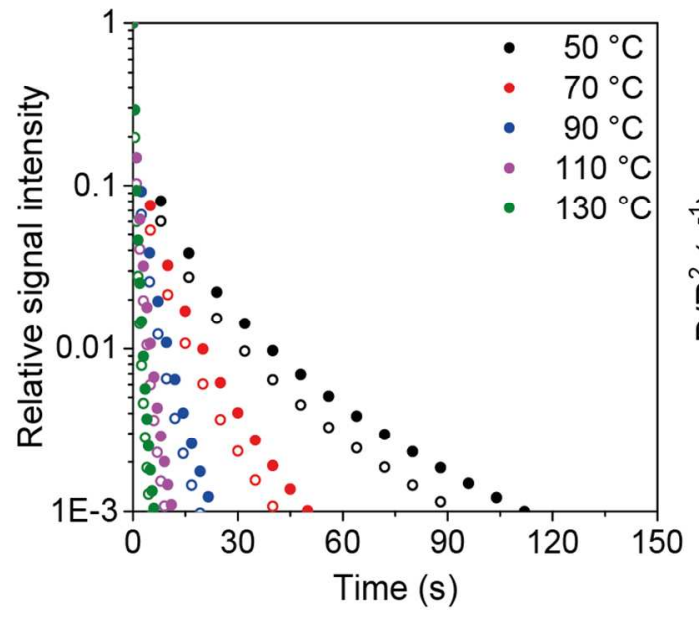

(a)

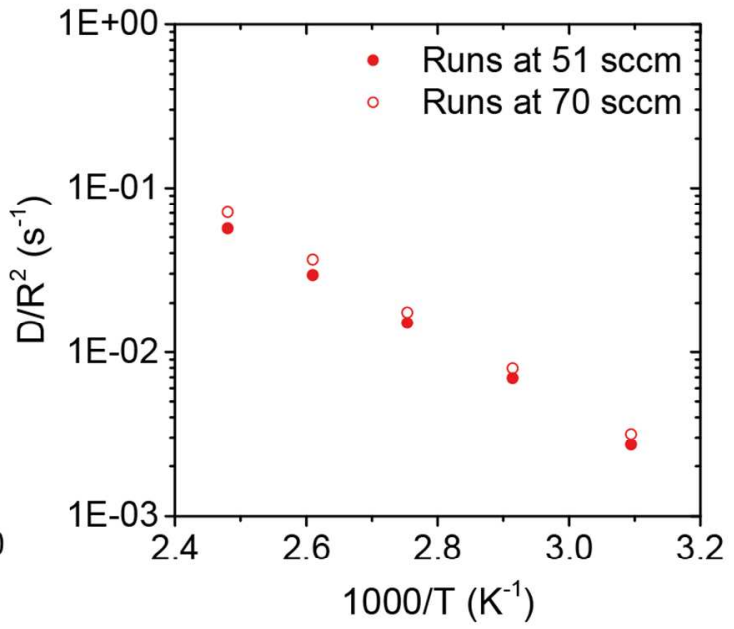

(b)

Figure S4. (a) ZLC curves for cyclohexane in SBA-15 $8.5 \mathrm{~nm}$ measured at diff flow rates. The filled circles represent the curves at lower flow rate $(51 \mathrm{sccm})$ while the empty circles represent the curves at higher flow rate $(70 \mathrm{sccm})$. (b) Arrhenius plot showing corresponding diffusivities measured.

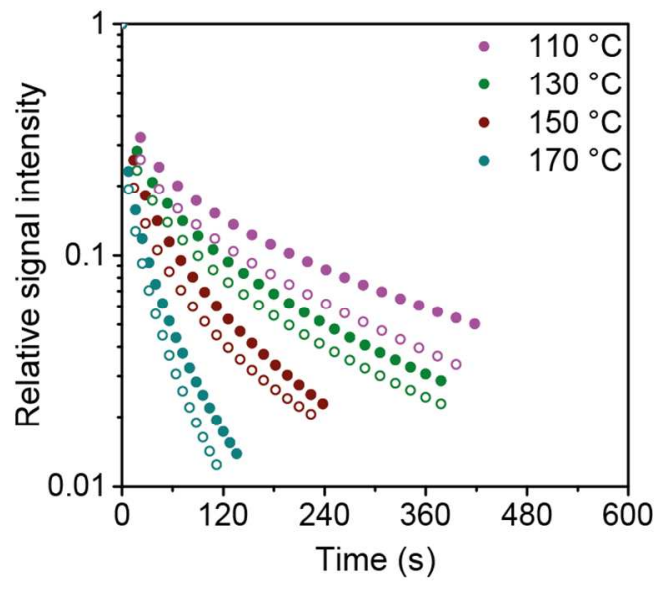

(a)

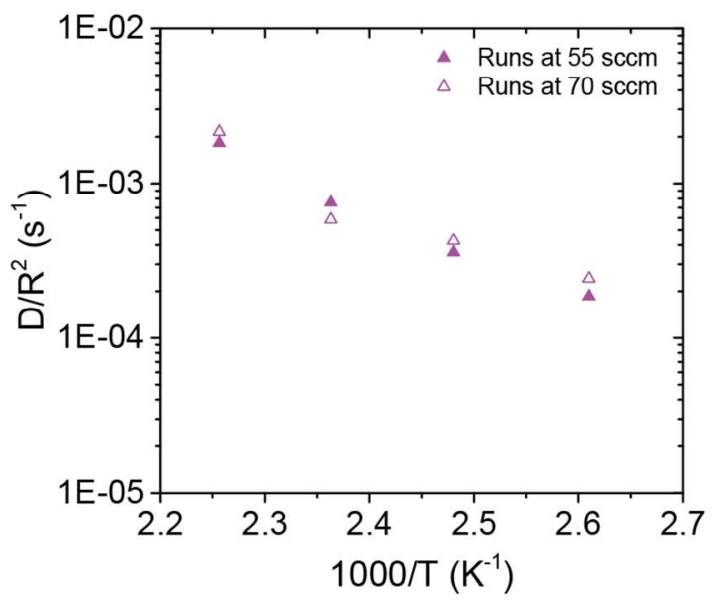

(b)

Figure S5. (a) ZLC curves 1-methylnaphthalene in SBA-15 $8.5 \mathrm{~nm}$ measured at diff flow rates. The filled circles represent the curves at lower flow rate $(55 \mathrm{sccm})$ while the empty circles represent the curves at higher flow rate $(70 \mathrm{sccm})$. (b) Arrhenius plot showing corresponding diffusivities measured. 


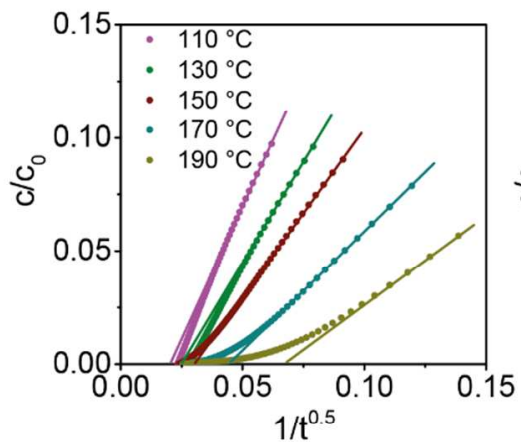

(a)

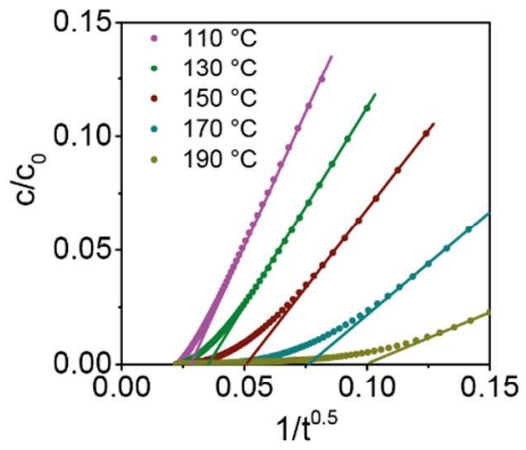

(c)

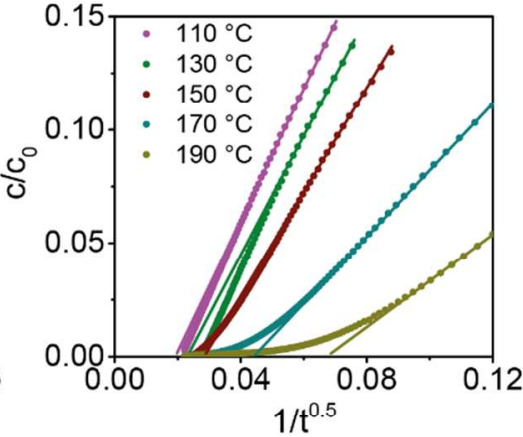

(b)

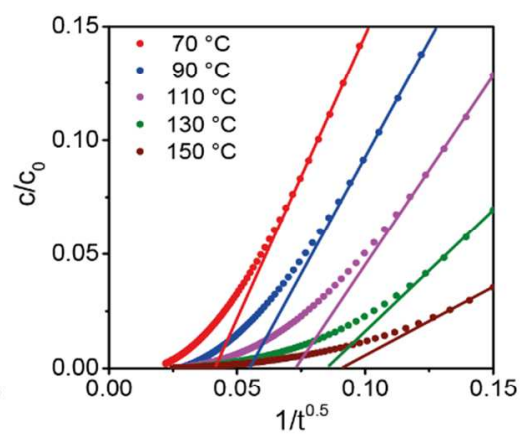

(d)

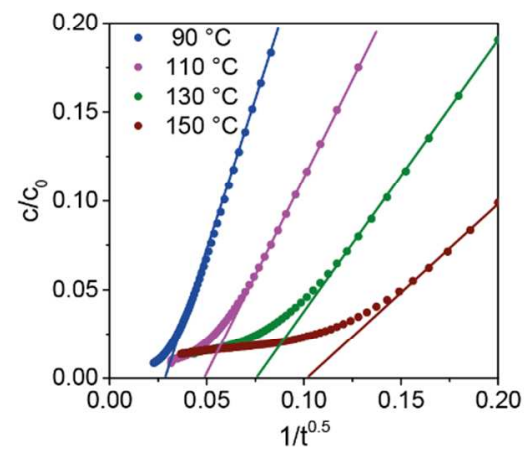

(e)

Figure S6. Plots of $\mathrm{c} / \mathrm{c}_{0}$ and $1 / \sqrt{ } \mathrm{t}$ for 1-methylnaphthalene in (a) SBA-15 $5 \mathrm{~nm}$, (b) SBA-15 $6.2 \mathrm{~nm}$, (c) SBA-15 $8.5 \mathrm{~nm}$, (d) 3DOm-i silicalite-1, and (e) MCM-41. 


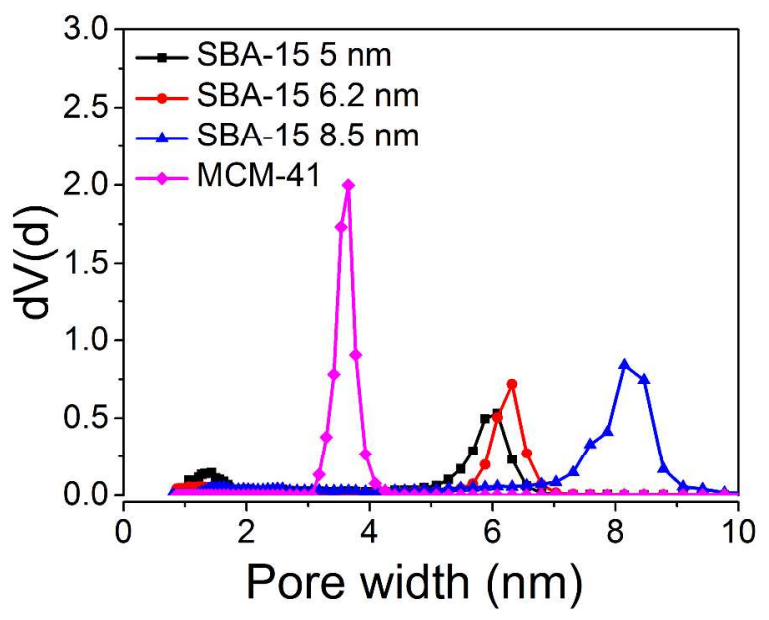

Figure S7. Pore size distributions as obtained from $\mathrm{N}_{2}$ adsorption at $77 \mathrm{~K}$ for MCM-41 and SBA-15. These were obtained using NLDFT model for $\mathrm{N}_{2}$ adsorption in cylindrical pores of silica at $77 \mathrm{~K}$.

Wide angle X-ray Diffraction pattern for 3DOm-i silicalite-1

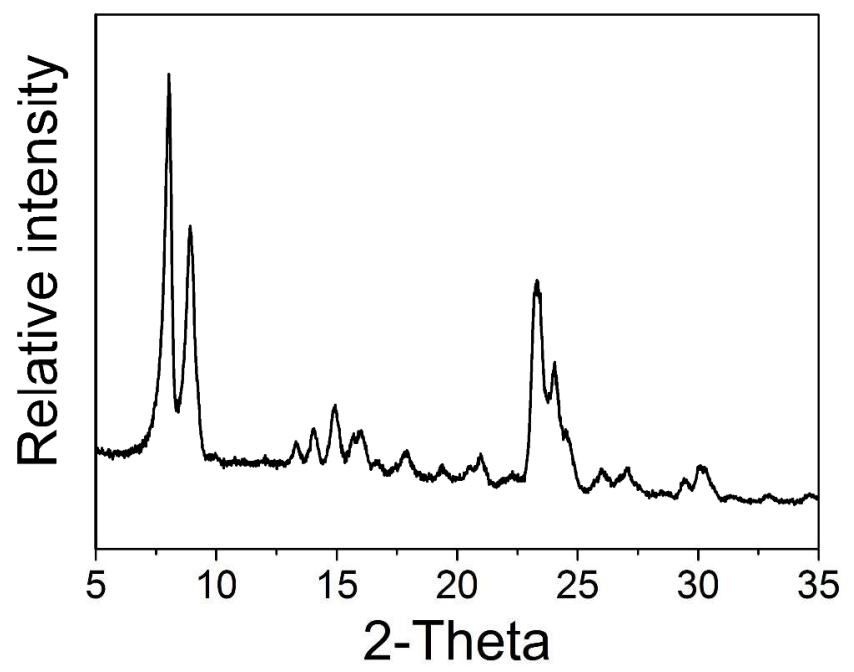

Figure S8. Wide angle X-ray Diffraction pattern for 3DOm-i silicalite-1 used in this study 
Table S1. Cumulative pore volumes as measured from N2 adsorption at $77 \mathrm{~K}$ for all the samples used in this study

\begin{tabular}{lc}
\hline Sample & $\begin{array}{c}\text { Total pore volume } \\
(\mathrm{cc} / \mathrm{g})\end{array}$ \\
\hline SBA-15 5 nm & 0.54 \\
SBA-15 $6.2 \mathrm{~nm}$ & 0.60 \\
SBA-15 $8.5 \mathrm{~nm}$ & 1.08 \\
3DOm-i silicalite-1 & 0.26 \\
MCM-41 & 0.77 \\
\hline
\end{tabular}

Table S2. Effective diffusion lengths as calculated for cyclohexane diffusion in all three SBA-15 samples and 3DOm-i silicalite-1. These lengths are several orders of magnitude different from the micropore length, which is about the size of individual spheres of around $35 \mathrm{~nm}$.

\begin{tabular}{cc}
\hline $\begin{array}{c}\text { Temperature } \\
\left({ }^{\circ} \mathrm{C}\right)\end{array}$ & $\begin{array}{c}\text { Effective diffusion length } \\
(\mu \mathrm{m})\end{array}$ \\
\hline 70 & $9.22 \mathrm{E}+04$ \\
90 & $6.98 \mathrm{E}+04$ \\
110 & $5.45 \mathrm{E}+04$ \\
130 & $4.02 \mathrm{E}+04$ \\
\hline
\end{tabular}


Table S3. Effective diffusion lengths calculated for cyclohexane diffusion in three SBA-15 samples and 3 DOm-i silicalite-1 using particle radius $\left(R_{\text {part }}\right)$ and pore wall half-thickness $\left(R_{\text {wall }}\right)$.

\begin{tabular}{|c|c|c|c|c|c|}
\hline & $\begin{array}{c}1000 / \mathrm{T} \\
\left(\mathrm{K}^{-1}\right)\end{array}$ & $\begin{array}{c}\text { 3DOm-i } \\
\text { silicalite-1 }\end{array}$ & $\begin{array}{l}\text { SBA-15 } \\
5 \mathrm{~nm}\end{array}$ & $\begin{array}{c}\text { SBA-15 } \\
6.2 \mathrm{~nm}\end{array}$ & $\begin{array}{l}\text { SBA-15 } \\
8.5 \mathrm{~nm}\end{array}$ \\
\hline \multirow{3}{*}{$D / R^{2}\left(\mathrm{~s}^{-1}\right)$} & 3.09 & 6.19 E-05 & 2.70 E-04 & $1.57 \mathrm{E}-03$ & $2.70 \mathrm{E}-03$ \\
\hline & 2.91 & 6.84 E-05 & 7.13 E-04 & $3.58 \mathrm{E}-03$ & $6.91 \mathrm{E}-03$ \\
\hline & 2.75 & $1.19 \mathrm{E}-04$ & $1.72 \mathrm{E}-03$ & $8.56 \mathrm{E}-03$ & $1.51 \mathrm{E}-02$ \\
\hline$R_{\text {part }}(\mu \mathrm{m})$ & -- & 2 & 0.4 & 0.45 & 0.55 \\
\hline \multirow{3}{*}{$D_{a p p}\left(\mathrm{~cm}^{2} \mathrm{~s}^{-1}\right)$} & 3.09 & 2.48 E-12 & $4.33 \mathrm{E}-13$ & $3.18 \mathrm{E}-12$ & $8.17 \mathrm{E}-12$ \\
\hline & 2.91 & 2.73 E-12 & $1.14 \mathrm{E}-12$ & $7.25 \mathrm{E}-12$ & 2.09 E-11 \\
\hline & 2.75 & 4.78 E-12 & $2.75 \mathrm{E}-12$ & $1.73 \mathrm{E}-11$ & $4.56 \mathrm{E}-11$ \\
\hline \multirow[t]{2}{*}{$\mathrm{R}_{\mathrm{wall}}(\mathrm{nm})$} & -- & 17.5 & $\underline{3.4}$ & 2.2 & 1.7 \\
\hline & 3.09 & $1.90 \mathrm{E}-16$ & 3.04 E-17 & $7.60 \mathrm{E}-17$ & $7.80 \mathrm{E}-17$ \\
\hline \multirow[t]{2}{*}{$D_{a p p}\left(\mathrm{~cm}^{2} \mathrm{~s}^{-1}\right)$} & 2.91 & $2.09 \mathrm{E}-16$ & $8.01 \mathrm{E}-17$ & 1.73 E-16 & $2.00 \mathrm{E}-16$ \\
\hline & 2.75 & 3.66 E-16 & 1.93 E-16 & 4.14 E-16 & $4.36 \mathrm{E}-16$ \\
\hline
\end{tabular}

Table S4. Calculated values of mean free path under the measurement conditions for cyclohexane and 1methylnaphthalene diffusion in the samples.

\begin{tabular}{lcccc}
\hline & \multicolumn{2}{c}{ Cyclohexane diffusion } & \multicolumn{2}{c}{$\begin{array}{c}\text { 1-methylnaphthalene } \\
\text { diffusion }\end{array}$} \\
\cline { 2 - 5 } Sample & $\begin{array}{c}\text { Temperature } \\
\text { range } \\
\left({ }^{\circ} \mathrm{C}\right)\end{array}$ & $\begin{array}{c}\text { Mean free } \\
\text { path } \\
(\mathrm{nm})\end{array}$ & $\begin{array}{c}\text { Temperature } \\
\text { range } \\
\left({ }^{\circ} \mathrm{C}\right)\end{array}$ & $\begin{array}{c}\text { Mean free } \\
\text { path } \\
(\mathrm{nm})\end{array}$ \\
\hline SBA-15 & $50-130$ & $46-60$ & $110-190$ & $44-55$ \\
3DOm-i silicalite-1 & $110-190$ & $57-71$ & $70-150$ & $38-49$ \\
MCM-41 & $40-70$ & $45-50$ & $90-150$ & $41-49$ \\
\hline
\end{tabular}

\section{References}

(1) Chang, C.-C.; Teixeira, A. R.; Li, C.; Dauenhauer, P. J.; Fan, W., Enhanced Molecular Transport in Hierarchical Silicalite-1. Langmuir 2013, 29, 13943-13950.

(2) Hufton, J. R.; Ruthven, D. M., Diffusion of light alkanes in silicalite studied by the zero length column method. Ind. Eng. Chem. Res. 1993, 32, 2379-2386.

(3) Cavalcante, C. L.; Brandani, S.; Ruthven, D. M., Evaluation of the main diffusion path in zeolites from ZLC desorption curves. Zeolites 1997, 18, 282-285. 
(4) Kärger, J.; Ruthven, D. M.; Theodorou, D. N. Diffusion in Nanoporous Materials $2^{\text {nd }}$ Edition; Wiley, 2012.

(5) Cavalcante, C. L., Jr.; Ruthven, D. M., Adsorption of Branched and Cyclic Paraffins in Silicalite. 1. Equilibrium. Ind. Eng. Chem. Res. 1995, 34, 177-184.

(6) Long, Y., Xu, T., Sun, Y., Dong, W., Adsorption Behavior on Defect Structure of Mesoporous Molecular Sieve MCM-41. Langmuir 1998, 14, 6173-6178.

(7) Bavel, E. V., Meynen, V., Cool, P., Lebeau, K., Vansant, E. F., Adsorption of Hydrocarbons on Mesoporous SBA-15 and PHTS Materials. Langmuir 2005, 21, 2447-2453.

(8) Ling, H. Zeolites and related materials: Trends, targets and challenges, Elsevier, 2008.

(9) Magalhães, F. D.; Laurence, R. L.; Conner, W. C., Diffusion of Cyclohexane and AlkylCyclohexanes in Silicalite. The Journal of Physical Chemistry B 1998, 102, 2317-2324.

(10) Song, L.; Rees, L. V. C., Adsorption and diffusion of cyclic hydrocarbon in MFI-type zeolites studied by gravimetric and frequency-response techniques. Microporous Mesoporous Mater. 2000, 35-36, 301-314.

(11) Song, L.; Sun, Z.-L.; Rees, L. V. C., Experimental and molecular simulation studies of adsorption and diffusion of cyclic hydrocarbons in silicalite-1. Microporous Mesoporous Mater. 2002, 55, 31-49.

(12) Brandani, S.; Ruthven, D. M., Analysis of ZLC desorption curves for gaseous systems. Adsorption 1996, 2, 133-143. 